\title{
A Review of Layered Double Hydroxides as Intermediate-temperature $\mathrm{CO}_{2}$ Adsorbents
}

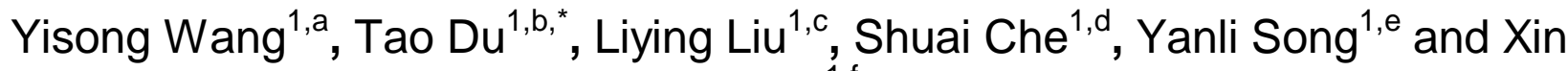 \\ Fang $^{1, f}$ \\ ${ }^{1}$ SEP Key Laboratory of Eco-Industry, Northeastern University, Shenyang \\ ayisonge@foxmail.com, bdut@smm.neu.edu.cn, ${ }^{\mathrm{c} l i u l y @ s m m . n e u . e d u . c n, ~}{ }^{\mathrm{d}} \mathrm{cesuai@163.com,}$ \\ esyjz_song@163.com, fang_xin1990@163.com \\ ${ }^{*}$ Corresponding author
}

\begin{abstract}
Keywords: Layered double hydroxides; Carbon dioxide; Intermediate-temperature adsorbents Abstract. Carbon dioxide capture technologies and solid adsorbents have been a rapid development with the human face increasingly severe environmental problems. Layered double hydroxides (LDH) is a kind of intermediate-temperature solid adsorbent, which is expected to have a useful application prospect. In this review, the classification of the adsorbent, the characteristics and synthesis methods of $\mathrm{LDH}$ are described. In the last section, the research progress and several research trends of LDH in the improvement of the adsorption performance of $\mathrm{CO}_{2}$ were discussed.
\end{abstract}

\section{Introduction}

$\mathrm{CO}_{2}$ is the principal anthropogenic greenhouse gas (GHG) of large point sources including fossil fuel power plants, fuel processing plants, and allied industrial plants in the atmosphere [1]. Among various carbon dioxide capture and storage (CCS) technical options for $\mathrm{CO}_{2}$ separation and capture, adsorption of $\mathrm{CO}_{2}$ on solid adsorbents have been widely investigated. In recent years, layered double hydroxides ( $\mathrm{LDH})$ are the most promising candidates for the above applications, due to the characteristics of eco-friendly, cheap, easy to regenerate, wide range of process technology [2]. Especially, $\mathrm{LDH}$ as intermediate-temperature $\left(200 \sim 400{ }^{\circ} \mathrm{C}\right) \mathrm{CO}_{2}$ adsorbents have been extensively studied due to their optimal adsorption reaction temperature in the industrial flue gas temperature range. This review described in detail from three aspects: types of $\mathrm{CO}_{2}$-adsorbents by the adsorption, the synthesis methods and research progress and trends of $\mathrm{LDH}$ adsorption on $\mathrm{CO}_{2}$. The characteristics, the advantages and the research trend of LDH as intermediate-temperature adsorbents were expatiated.

\section{Types of $\mathrm{CO}_{2}$-adsorbents by the Adsorption Temperature}

The solid $\mathrm{CO}_{2}$-adsorbents can be classified into three types according to the reaction temperature of the adsorption process: low-, intermediate- and high-temperature adsorbents with temperatures ranging from below $200{ }^{\circ} \mathrm{C}$, between $200 \sim 400{ }^{\circ} \mathrm{C}$ and above $400{ }^{\circ} \mathrm{C}$, respectively [3].

Low-temperature Adsorbents. Low-temperature adsorbents mainly including zeolite based adsorbents [4, 5], carbon based adsorbents [6, 7] and metal organic framework based adsorbents [8-10] always have received extensive attention, especially in recent years. Zeolites are porous crystalline aluminosilicates, whose framework of $\mathrm{SiO}_{4}$ and $\mathrm{AlO}_{4}$ joined together in various regular arrangements through shared oxygen atoms. In addition to biomass or coal as the precursor of activated carbon, carbon based adsorbents also include carbon nanotubes [11], nanoporous carbon fibres [12] and ordered mesoporous carbon [13]. Due to their low cost, high surface area, high adsorption capacity and high amenability to pore structure modification, especially relative ease of regeneration, Low-temperature adsorbents were considered to be one of the most promising adsorbents for capturing $\mathrm{CO}_{2}$ in industrial production. However, their adsorption capacity increases with decreasing temperature, and the maximum adsorption capacity is usually at $0{ }^{\circ} \mathrm{C}$ without the 
discussion below $0{ }^{\circ} \mathrm{C}$. The $\mathrm{CO}_{2}$ sorption capacity drops dramatically at temperatures associated with power plant flue gas $\left(50 \sim 120^{\circ} \mathrm{C}\right)[14]$.

High-temperature Adsorbents. High-temperature adsorbents mainly including solid metal oxide based adsorbents and calcium based adsorbents. Under high temperature, the formation of metal carbonate by chemical reaction between the solid metal oxide based adsorbents and $\mathrm{CO}_{2}$ gas $[15,16]$. At higher temperatures, the metal carbonates are redecomposed into metal oxides and $\mathrm{CO}_{2}$, achieving the recovery of $\mathrm{CO}_{2}$ and the regeneration of the adsorbent. Many metal oxides, such as $\mathrm{ZnO}, \mathrm{CuO}$, $\mathrm{PbO}$ and $\mathrm{Li}_{2} \mathrm{O}$ have similar reaction characteristics. $\mathrm{CaO}$ is regarded as the preferred material of calcium based adsorbents in the process of high temperature $\mathrm{CO}_{2}$ adsorption, because of its wide raw material sources, low cost and simple preparation process [17]. However, at high temperature, the work of the adsorbent is easy to sintering, and the stability of the cycle is poor at about $900{ }^{\circ} \mathrm{C}$, which means that it is not easy to completely regenerate.

Layered Double Hydroxides Intermediate-temperature Adsorbents. Layered double hydroxides (LDH), also known as hydrotalcite-like compounds (HT) or anionic clays are layered basic solids, and it was a typical intermediate-temperature adsorbent [18]. In addition, it has been widely used as ion exchangers, base catalysts, and precursors of well-mixed oxides for various catalytic applications [19]. The chemical composition of LDH materials are represented by the general formula $\left[\mathrm{M}_{(1-\mathrm{x})}{ }^{2+} \mathrm{M}_{\mathrm{x}}{ }^{3+}(\mathrm{OH})_{2}\right] \mathrm{A}_{\mathrm{x} / \mathrm{n}}{ }^{\mathrm{n}-} \cdot \mathrm{mH}_{2} \mathrm{O}$, in which, where $\mathrm{M}^{2+}$ and $\mathrm{M}^{3+}$ are divalent $\left(\mathrm{Mg}^{2+}, \mathrm{Zn}^{2+}, \mathrm{Ni}^{2+}\right.$, etc. $)$ and trivalent cations $\left(\mathrm{Al}^{3+}, \mathrm{Ga}^{3+}, \mathrm{Fe}^{3+}, \mathrm{Mn}^{3+}\right.$, etc.) respectively, $\mathrm{A}^{\mathrm{n}-}$ are various interlayer inorganic anions or organic anions with negative charge $n, x$ is the value of the $\mathrm{M}^{3+} /\left(\mathrm{M}^{2+}+\mathrm{M}^{3+}\right)$ ratio, and the synthesis of pure hydrotalcite need $\mathrm{x}$ in a range of $0.2 \sim 0.4$, and $\mathrm{m}$ is the number of interlayer water molecules [20]. The best working temperature of $\mathrm{LDH}$ at $200 \sim 400{ }^{\circ} \mathrm{C}$, the temperature is the temperature range of industrial flue gas, such as low-pressure superheater to the chimney in the exhaust system in power plant. Therefore, it was not necessary to reduce the temperature of flue gas. Also, it did not require a very high temperature for its regeneration, and even can be used for pressure swing adsorption process.

\section{The Synthesis Method of Layered Double Hydroxides}

According to the intercalation theory and the crystallographic theory in synthetic chemistry, the solution concentration and temperature could be adjusted to control the nucleation rate of the crystal in LDH nucleation. Moreover, the crystallization time and crystallization method could be used to control the crystal growth rate. In addition, the synthesis method of LDH was very important for controlling crystal morphology and crystal properties.

Co-precipitation Method. Co-precipitation method is the most commonly used method for the preparation of LDH [21]. This method first uses a LDH laminate metal ion solution and alkaline solution mixed by a certain method, finally co-precipitation reaction, in which metal ions in the mixed solution or alkaline solution containing anionic species composition LDH. Then the colloidal crystallization to obtain the target product can be crystallized under certain conditions. The basic conditions of co precipitation solution is supersaturated. There are a variety of conditions to achieve the supersaturation, commonly used $\mathrm{pH}$ value adjustment method, the most critical point is that the $\mathrm{pH}$ value of precipitation must be higher or at least equal to the $\mathrm{pH}$ value of the most difficult soluble metal hydroxide precipitate.

Calcination-regeneration Method. This method is based on the characteristics of the structure memory effect of LDH. At a certain temperature, the LDH of the calcined product of double metal oxide was added to the solution containing some kind of anion, then the LDH layer structure was rebuilt, the anion into the layer, forming a new structure of LDH [22]. The general firing temperature is within $500{ }^{\circ} \mathrm{C}$, and the heating rate is too fast to cause the structural damage.

Other Methods. The template synthesis method [23], surface in-situ method [24], gas-liquid contact method [25] and microwave crystallization method [26] is not very extensive application in the LDH system, which still needs further in-depth research and development in the reaction principle, control conditions and so on. 


\section{Research Progress and Trends of $\mathrm{LDH}$ Adsorption on $\mathrm{CO}_{2}$}

Although LHD has many advantages in the adsorption of $\mathrm{CO}_{2}$, there were still a lot of problems to be overcome in practical applications. In order to improve the adsorption capacity of LDH, the scholars have studied the conditions of synthesis, modification and compounding.

Heat Treatment. Fresh LDH does not possess any basic sites, so it is necessary to heat treatment. Then it gradually loses interlayer water, $\mathrm{OH}^{-}$and $\mathrm{CO}_{3}{ }^{2-}$. Yang et al. [27] proposed structure change model of heat-treated Mg-Al- $\mathrm{CO}_{3} \mathrm{LDH}$, through the application of HTXRD and TG / MS techniques. Reddy et al. [28] reported that the sample calcined at $400{ }^{\circ} \mathrm{C}$ showed the highest adsorption capacity, which is presumably due to the trade-off between the surface area and availability of active basic sites.

K Ions Doping Modification. Oliveira et al. [29] reported that three kinds of LDH (MG 30, MG 40 and MG 50) were modified with $\mathrm{K}$ and Cs ions doping, by comparison, found that Adsorption capacity of a modified MG 30 with $\mathrm{K}$ ions was increased from $<0.1$ to $0.76 \mathrm{mmol} / \mathrm{g}$. Walspurger et al. [30] studied the mechanism of $\mathrm{K}$ ions to improve the adsorbent performance, and found that $\mathrm{K}$ ions interact with the alumina center play an important role to generates basic sites at $300-500{ }^{\circ} \mathrm{C}$.

Composite with Supporting Materials. Adsorption capacity of LDH could be enhanced by composite with porous supporting materials such as zeolites, activated carbon and Mesoporous silica. Bhatta et al. [31] reported that in order to improve the adsorption capacity of LDH and keep the best reaction temperature, they found a kind of coal based porous carbon material, which was an economical natural source of carbon. Pramod et al. [32] synthesized LDH-SBA-15 composite materials, which were mesoporous, versatile, eco-friendly and repeatable $\mathrm{CO}_{2}$ capture materials. The porous supporting materials not only increase the adsorption capacity and the adsorption diffusion rate, but also have an existence of synergy between both the parent materials. So the composite material is the development trend of LDH research in the future, because it can play the advantages of each component.

\section{Conclusions}

Layered double hydroxides ( $\mathrm{LDH}$ ) as intermediate-temperature $\mathrm{CO}_{2}$ adsorbents have been extensively studied due to their optimal adsorption reaction temperature in the industrial flue gas temperature range. They are also given the characteristics of eco-friendly, cheap, easy to regenerate, wide range of process technology and so on. Moreover, LDH have gained and will continuously obtain global interests for applications in adsorption, separation, catalysis, ion exchange and storages. However, further research is needed to improve the adsorption properties of LDH by means of synthetic methods, modification, and composite with supporting materials exploration. Clearly, numerous challenges remain, but the rate of advance in layered double hydroxides materials over the past decade promises that this area will bring encouraging results in $\mathrm{CO}_{2}$ adsorption applications.

\section{Acknowledgements}

This work was financially supported by the Natural Science Foundation of China (Grant Nos. 51474067 and 51406029) and "123" Project of China Environment Protection Foundation (No. CEPF 2013-123-2-14).

\section{References}

[1] Yanai, M., Koch, J., Dayan, U.: Clim. Change Vol. 101 (2010), p. 555-563

[2] Ramírez-Moreno, M.J., Romero-Ibarra, I.C., Hernández-Pérez, M.A.: Ind. Eng. Chem. Res. Vol. 53 (2014), p. 8087-8094 (2014) 
[3] Wang, Q., Luo, J., Zhong, Z., Borgna, A.: Energy Env. Sci. Vol. 4 (2011), p. $42-55$ (2011)

[4] Thang, H.V., Grajciar, L., Nachtigall, P., Bludsky, O., Otero Arean, C., Frydova, E., Bulanek, R.: Catal. Today Vol. 227 (2014), p. 50-56

[5] Aguilar-Armenta, G., Hernandez-Ramirez, G.: J. Phys. Chem. B. Vol. 105 (2001), p. 1313-1319

[6] Kwon, T.-H., Huh, S.: Bull. Korean Chem. Soc. Vol. 31 (2010), p. 3507-3508

[7] Ello, A.S., de Souza, L.K.C., Trokourey, A., Jaroniec, M.: Microporous Mesoporous Mater. Vol. 180 (2013), p. 280-283

[8] Uzun, A., Keskin, S.: Prog. Surf. Sci. Vol. 89 (2014), p. 56-79

[9] Bose, P., Bai, L., Ganguly, R., Zou, R., Zhao, Y.: Chempluschem. Vol. 80 2015, p. 1259

[10] Demessence, A., Long, J.R.: Chem. Eur. J. Vol. 16 (2010), p. 5902-5908

[11] Liu, L., Nicholson, D., Bhatia, S.K.: Chem. Eng. Sci. Vol. 121 (2015), p. 268-278

[12] Villar-Rodil, S., Martinez-Alonso, A., Tascon, J.M.D.: J. Therm. Anal. Calorim. Vol. 79 (2005), p. $529-532$

[13] Meng, Y., Gu, D., Zhang, F., Shi, Y., Cheng, L., Feng, D., Wu, Z., Chen, Z., Wan, Y., Stein, A., Zhao, D.: Chem. Mater. Vol. 18 (2006), p. 4447-4464

[14] Arenillas, A., Smith, K.M., Drage, T.C., Snape, C.E.: Fuel. Vol. 84 (2005), 2204-2210

[15] Ueda, S., Inoue, R., Sasaki, K., Wakuta, K., Ariyama, T.: Isij Int. Vol. 51 (2011), p.530-537

[16] Mosqueda, H.A., Vazquez, C., Bosch, P.: Chem. Mater. Vol. 18 (2006), p. 2307-2310

[17] Baciu, D., Steriotis, T., Charalambopoulou, G., Stubos, A.: J. Optoelectron. Adv. Mater. Vol. 18 (2016), p. 378-382

[18] Parida, K., Das, J.: J. Mol. Catal. Chem. Vol. 151 (2000), p. 185-192

[19] Cavani, F., Trifirò, F., Vaccari, A.: Catal. Today. Vol. 11 (1991), p. 173-301

[20] Ram Reddy, M.K., Xu, Z.P., Lu, G.Q. Ind. Eng. Chem. Res. Vol. 45 (2006), p. 7504-7509

[21] Seftel, E.M., Popovici, E., Mertens, M., De Witte, K., Van Tendeloo, G., Cool, P., Vansant, E.F.: Microporous Mesoporous Mater. Vol. 113 (2008), p. 296-304

[22] Chibwe, K., Jones, W.: J. Chem. Soc. Chem. Commun. Vol. 75 (1989), p.926

[23] He, J.X., Kobayashi, K., Takahashi, M.: Thin Solid Films. Vol. 397 (2001), p. 255-265

[24] Zhang, X., Wang, N., Xu, Y., Yin, Y., Shang, S.: Catal. Commun. Vol. 45 (2014), p. 11-15

[25] Lei, X., Yang, L., Zhang, F., Duan, X.: Chem. Eng. Sci. Vol. 61 (2006), p. 2730-2735

[26] Wang, L., Li, B., Chen, C., Jia, L.: J. Alloys Compd. Vol. 508 (2010), p. 426-432

[27] Yang, W., Kim, Y., Liu, P.K.T., Sahimi, M.: Chem. Eng. Sci. VOl. 57 (2002), p. 2945-2953

[28] Ram Reddy, M.K., Xu, Z.P., Lu, G.Q.: Ind. Eng. Chem. Res. Vol. 45 (2006), p. 7504-7509

[29] Oliveira, E.L.G., Grande, C.A., Rodrigues.: Sep. Purif. Technol. Vol. 62 (2008), p. 137-147

[30] Walspurger, S., Boels, L., Cobden: ChemSusChem. Vol.1 (2008), p.643-650

[31] Bhatta, L.K.G., Subramanyam, S., Chengala, M.D., Bhatta, U.M., Venkatesh, K.: Ind. Eng. Chem. Res. Vol. 54 (2015), p. 10876-10884

[32] Pramod, C.V., Upendar, K., Mohan, V., Sarma, D.S., Dhar, G.M., Prasad, P.S.S., Raju, B.D., Rao, K.S.R.: J. $\mathrm{CO}_{2}$ Util. Vol. 12 (2015), 109-115 
